\title{
Repression of btuB gene transcription in Escherichia coli by the GadX protein
}

\author{
Guang-Sheng Lei ${ }^{1}$, Wan-Jr Syu ${ }^{1}$, Po-Huang Liang ${ }^{2}$, Kin-Fu Chak ${ }^{3}$, Wensi S Hu${ }^{4}$, Shiau-Ting Hu ${ }^{1,5^{*}}$
}

\begin{abstract}
Background: BtuB (B twelve uptake) is an outer membrane protein of Escherichia coli, it serves as a receptor for cobalamines uptake or bactericidal toxin entry. A decrease in the production of the BtuB protein would cause $E$. coli to become resistant to colicins. The production of BtuB has been shown to be regulated at the posttranscriptional level. The secondary structure switch of $5^{\prime}$ untranslated region of butB and the intracellular concentration of adenosylcobalamin (Ado-Cbl) would affect the translation efficiency and RNA stability of btuB. The transcriptional regulation of btuB expression is still unclear.

Results: To determine whether the btuB gene is also transcriptionally controlled by trans-acting factors, a genomic library was screened for clones that enable E. coli to grow in the presence of colicin E7, and a plasmid carrying gadX and gadY genes was isolated. The lac $Z$ reporter gene assay revealed that these two genes decreased the btuB promoter activity by approximately $50 \%$, and the production of the BtuB protein was reduced by approximately $90 \%$ in the presence of a plasmid carrying both gadX and gadY genes in E. coli as determined by Western blotting. Results of electrophoretic mobility assay and DNase I footprinting indicated that the GadX protein binds to the $5^{\prime}$ untranslated region of the btuB gene. Since gadX and gadY genes are more highly expressed under acidic conditions, the transcriptional level of btuB in cells cultured in pH 7.4 or pH 5.5 medium was examined by quantitative real-time PCR to investigate the effect of GadX. The results showed the transcription of gadX with 1.4-fold increase but the level of btuB was reduced to $57 \%$.

Conclusions: Through biological and biochemical analysis, we have demonstrated the GadX can directly interact with btuB promoter and affect the expression of btuB. In conclusion, this study provides the first evidence that the expression of btuB gene is transcriptionally repressed by the acid responsive genes gadX and gadY.
\end{abstract}

\section{Background}

BtuB ( $\underline{B}$ twelve uptake) is a 614 amino acid outer membrane protein of Escherichia coli. It is responsible for the uptake of cobalamins [1], such as vitamin $B_{12}$ including cyanocobalamin, hydroxocobalamin, methylcobalamin, and adenosylcobalamin[2]. It also serves as the receptor for bacteriophage BF23 [3]. The synthesis of the BtuB protein in E. coli is regulated at the translational level by adenosylcobalamin (Ado-Cbl) which is produced by the BtuR protein (CobA in Salmonella typhimurium and CobO in Pseudomonas denitrificans) [4-6]. BtuR is an ATP:corrinoid adenosyltransferase and converts cobalamins to Ado-Cbl [4]. In the presence of

\footnotetext{
* Correspondence: tingnahu@ym.edu.tw

'Institute of Microbiology and Immunology, School of Life Science, National Yang-Ming University, Taipei 11221, Taiwan

Full list of author information is available at the end of the article
}

Ado-Cbl, the stability of the $b t u B$ mRNA is reduced with a half-life of only $2-4$ minutes [7]. In addition, Ado-Cbl binds to the leader region (5' untranslated region, 5' UTR) of the $b t u B$ mRNA and suppresses its translation $[8,9]$. A 25-nucleotide sequence designated as the $\mathrm{B}_{12}$-box located $+138-+162$ nucleotides downstream from the transcription initiation site of $b t u B$ in $E$. coli has been suggested to be the binding site of AdoCbl [10]. A $B_{12}$-box is also present in the 5' UTR of both $b t u B$ and cbiA genes of S. typhimurium [11]. The $b t u B$ gene of $S$. typhimurium is highly homologous to that of E. coli. The CbiA protein is a cobyrinic acid a, cdiamide synthase using cobyrinic acid as substrate $[10,12]$. Binding of Ado-Cbl to the 5' UTR of the mRNAs of these genes may interfere with ribosome binding and thus decrease their translation [7-9,13].

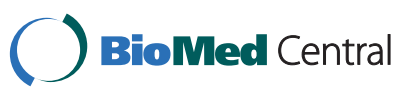

(ㄷ) 2011 Lei et al; licensee BioMed Central Ltd. This is an Open Access article distributed under the terms of the Creative Commons Attribution License (http://creativecommons.org/licenses/by/2.0), which permits unrestricted use, distribution, and reproduction in any medium, provided the original work is properly cited. 
It is unknown whether BtuB synthesis is also controlled by regulatory proteins at the transcriptional level. Results of this study suggest that GadX (Glutamic acid decarboxylation) is a transcriptional regulator of $\bar{b} \overline{t u} B$. GadX has been shown to suppress the expression of perA encoded by a plasmid of enteropathogenic $E$. coli [14], but activate $\operatorname{gad} X, \operatorname{gad} A, \operatorname{gad} B$, and $\operatorname{gad} C$ in response to acid stress [15-19]. GadA and GadB are isozymes of glutamate decarboxylases that convert glutamate to $\gamma$-aminobutyric acid (GABA) which is then exported by the antiporter protein GadC [20,21]. An intracellular proton is consumed during GABA production [22], but the released GABA, which is less acidic than glutamate, provides local buffering of the extracellular environment.

The expression of $\operatorname{gadX}$ is activated by the alternative sigma factor RpoS during the stationary phase of growth $[15,19,21]$, but is repressed during the exponential phase by the nucleoid protein $\mathrm{H}-\mathrm{NS}$ due to its binding to the gadX promoter or its destabilizing effect on RpoS [23-25]. However, the acid stress increases the RpoS level and thus induces gadX expression even during the exponential phase of growth [26]. GadW, like GadX, belongs to the family of AraC-like regulators. It represses the expression of $\operatorname{gad} X$ and inhibits the activation of $\operatorname{gadA}$ and $\operatorname{gad} B C$ by $\operatorname{GadX}[15,18,27]$. In addition to these trans-acting proteins, the production of GadX is also controlled by $\operatorname{gad} Y$ that is located between $\operatorname{gad} X$ and $\operatorname{gad} W$ in an opposite orientation to $\operatorname{gadX}[28,29]$. The $\operatorname{gad} Y$ gene has no known protein products. It produces three RNA species of 105,90 , and 59 nucleotides with a common 3' end [28]. The 3' ends of gadX and $\operatorname{gad} Y$ RNAs overlap by at least 30 nucleotides and are complementary to each other. Annealing of gadY RNA to the 3' end of $\operatorname{gadX}$ mRNA stabilizes $\operatorname{gad} X$ mRNA, resulting in an increased production of the GadX protein [28].

$\mathrm{BtuB}$ is also involved in the import of colicins such as colicin E7 (ColE7) [30-34]. ColE7 is composed of three domains responsible for the translocation of ColE7 through the OmpF porin, binding of ColE7 to BtuB, and cleavage of DNA $[35,36]$, respectively. The import of ColE7 is dependent on the Tol (tolerance to colicin) system that is composed of TolQ, TolR, TolA, and TolB proteins $[35,36]$. Deletion or mutation of BtuB, OmpF, or any of the Tol proteins renders $E$. coli resistant to ColE7 $[33,37,38]$. Based on this information, we used a ColE7 resistance assay in this study to search for transcriptional regulators of btuB from a genomic library of E. coli strain DH5 $\alpha$ and found that gadX and gadY genes down regulate the expression of $b t u B$.

\section{Results}

Screening of genes conferring $E$. coli resistance to ColE7 To search for genes that can confer $E$. coli resistance to ColE7, plasmids in the genomic library were transformed into the ColE7-sensitive E. coli strain DH5 $\alpha$, and the transformants were plated on LB agar plates containing $50 \mu \mathrm{g} / \mathrm{ml}$ of ampicillin and $5.0 \mathrm{ng} / \mathrm{ml}$ of $\mathrm{His}_{6}$-tagged ColE7/ImE7. Two colonies were seen after incubation at $37^{\circ} \mathrm{C}$ overnight. The plasmids of each colony were isolated after culturing in $3 \mathrm{ml} \mathrm{LB}$ medium containing 50 $\mu \mathrm{g} / \mathrm{ml}$ of ampicillin then retransformed into DH5 $\alpha$. The new transformants were plated on agar plates containing 0, 1.3, 2.6, 3.9, or $5.2 \mathrm{ng} / \mathrm{ml}$ of $\mathrm{His}_{6}$-tagged ColE7/ImE7 to confirm their resistance to ColE7. The insert in the plasmid that conferred DH5 $\alpha$ resistance to $5.2 \mathrm{ng} / \mathrm{ml}$ $\mathrm{His}_{6}$-tagged ColE7/ImE7 was sequenced. A 1,470-bp DNA region on the chromosome at position 3662617 to 3664086 was analyzed that contains both complete gadX and $\operatorname{gad} Y$ genes. The plasmid was thus named pGadXY (Figure 1).

To determine whether $\operatorname{gadX}$ or $\operatorname{gad} Y$ was responsible for ColE7 resistance, pGadX, pGadY, and pGadXY that contain $\operatorname{gad} X, \operatorname{gad} Y$, and $\operatorname{gad} X Y$, respectively, were separately introduced into $E$. coli strain $\mathrm{DH} 5 \alpha$ and then assayed for their ability to confer ColE7 resistance. $1 \times 10^{5}$ cells containing pGadX, pGadY, or pGadXY were plated on LB agar containing 1.3, 2.6, 3.9 , or $5.2 \mathrm{ng} / \mathrm{ml}$ of $\mathrm{His}_{6}$-tagged ColE7/ImE7. Cells containing the vector pGAD10 were also plated to serve as controls. The percent survival of cells containing pGAD10, pGadXY, pGadX, and pGadY in the presence of $1.3 \mathrm{ng} / \mathrm{ml}$ of $\mathrm{His}_{6}$-tagged ColE7/ImE7 were $41.7,95.5,71.4$, and $73.5 \%$, respectively, and 1.5, 63.9, 3.6 , and $9.1 \%$, respectively, in the presence of $2.6 \mathrm{ng} /$ $\mathrm{ml}$ of $\mathrm{His}_{6}$-tagged ColE7/ImE7. Only pGadXY conferred ColE7 resistance to 3.9 and $5.2 \mathrm{ng} / \mathrm{ml}$ of $\mathrm{His}_{6}-$ tagged ColE7/ImE7 with 29.1 and $17.1 \%$ survival rates, respectively (Table 1 ).

\section{Detection of protein whose expression is affected by $\operatorname{gadXY}$}

To investigate the mechanism by which $\operatorname{gad} X Y$ affects ColE7 resistance, the expression levels of BtuB, TolQ, TolR, TolA, TolB, Pal, and OmpF that are involved in ColE7 import were determined by Western blotting, and BtuB was the only protein found to be affected. Its expression level was reduced by $93 \%$ in the presence of $\operatorname{gadXY}$ (Figure 2) as determined by densitometry.

\section{Effect of gadXY on btuB promoter}

To determine whether $\operatorname{gadXY}$ affects the transcription of $b t u B$, the $\beta$-galactosidase reporter assay was performed. The 461-, 673-, 913-, and 1285-bp DNA fragments (Figure 3) containing the promoter of $b t u B$ were fused with the lac $Z$ coding sequence to generate $\mathrm{pCB}_{461}$ lac $Z$, $\mathrm{pCB}_{673}$ lac $Z$, $\mathrm{pCB}_{913}$ lac $Z$, and $\mathrm{pCB}_{1285}$ lac $Z$, respectively. Each of these single copy plasmid together with pGAD10 or pGadXY was transformed into E. coli strain 


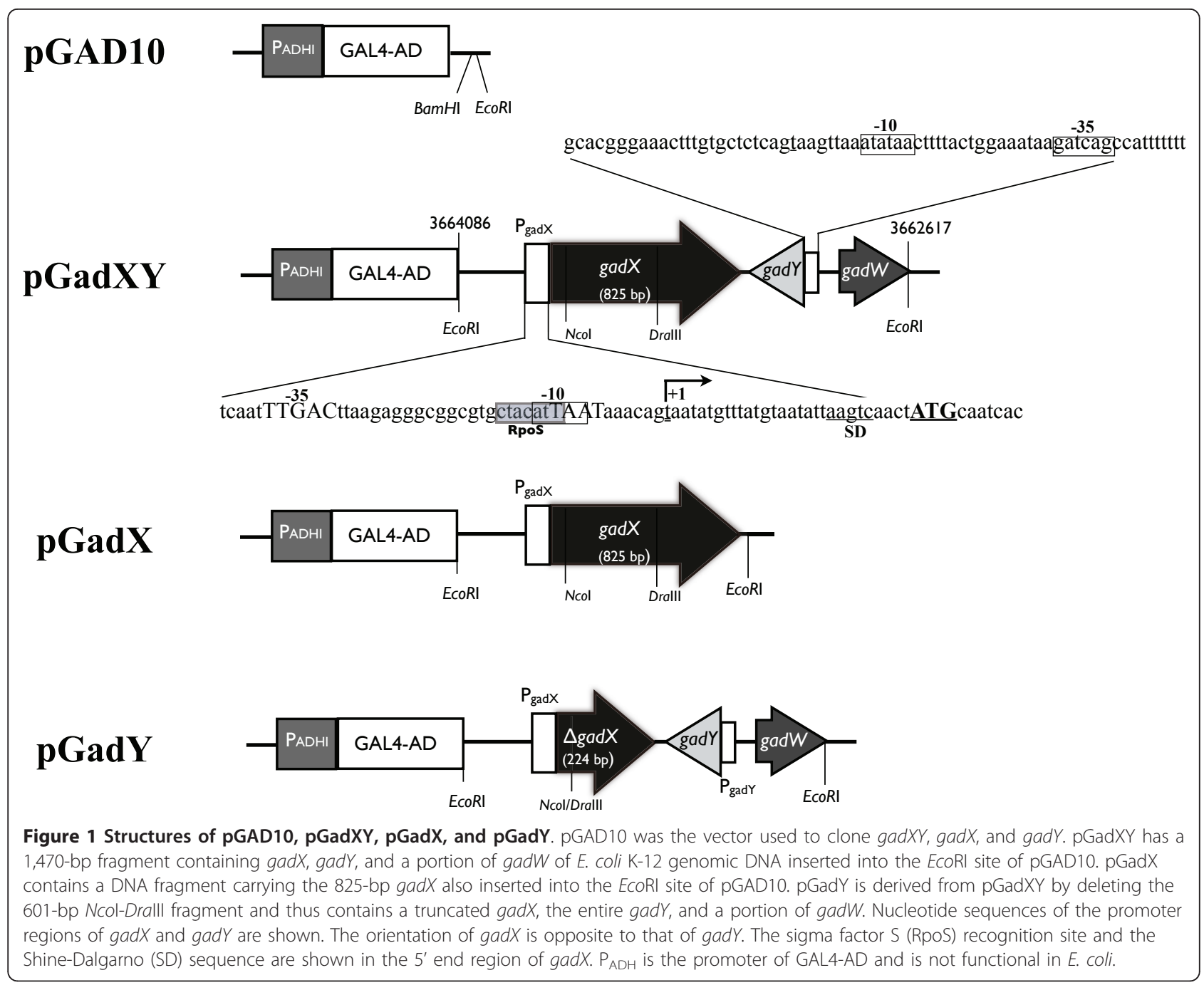

DH5 $\alpha$. The transformed cells were grown in LB medium with $50 \mu \mathrm{g} / \mathrm{ml}$ of chloramphenicol and ampicilin to $\mathrm{OD}_{600} \sim 0.8$ then assayed for $\beta$-galactosidase activity as described by Miller [39]. The $\beta$-galactosidase activity of cells containing pGadXY and a $\mathrm{pCB}$ derivative with the $b t u B$ promoter-lac $Z$ fusion was divided by that of cells containing the control plasmid pGAD10 and the same $\mathrm{pCB}$ derivative to determine the percent decrease in $b t u B$ promoter activity in the presence of $\operatorname{gad} X Y$. The btuB promoter in the 461-, 673-, 913-, and 1285-bp DNA fragment was found to be decreased by $45.7,47.1$,
54.5 , and $56.7 \%$, respectively in the presence of $\operatorname{gad} X Y$, and was about 6 fold more active in the 1285-bp fragment than in other fragments (Table 2).

To investigate the effect of $\operatorname{gadX}$ or $\operatorname{gad} Y$ alone on the promoter activity of $b t u B$, the same experiment was performed using $\mathrm{DH} 5 \alpha$ cells containing $\mathrm{pCB}_{1285}$ lac $\mathrm{Z}$ and pGAD10, pGadXY, pGadX, or pGadY. The $\beta$-galactosidase activity of cells containing $\mathrm{pCB}_{1285}$ lacZ and pGadXY, pGadX, or pGadY was compared to those containing pGAD10 and $\mathrm{pCB}_{1285}$ lacZ. The results indicated that $b t u B$ promoter activity was decreased $20.5 \%$ by

Table 1 Effects of gadXY, gadX, and gadY on ColE7 resistance

\begin{tabular}{ccccc}
\hline ColE7 conc./Bacteria & pGAD10/DH5 $\alpha$ & pGadXY/DH5 $\alpha$ & pGadX/DH5 $\boldsymbol{1}$ & pGadY/DH5 $\boldsymbol{\alpha}$ \\
\hline $1.3 \mathrm{ng} / \mathrm{ml}$ & $41.7 \%$ & $95.5 \%$ & $71.4 \%$ & $73.5 \%$ \\
\hline $2.6 \mathrm{ng} / \mathrm{ml}$ & $1.5 \%$ & $63.9 \%$ & $3.6 \%$ & $9.1 \%$ \\
\hline $3.9 \mathrm{ng} / \mathrm{ml}$ & 0 & $29.1 \%$ & 0 & 0 \\
\hline $5.2 \mathrm{ng} / \mathrm{ml}$ & 0 & $17.1 \%$ & 0 & 0 \\
\hline
\end{tabular}




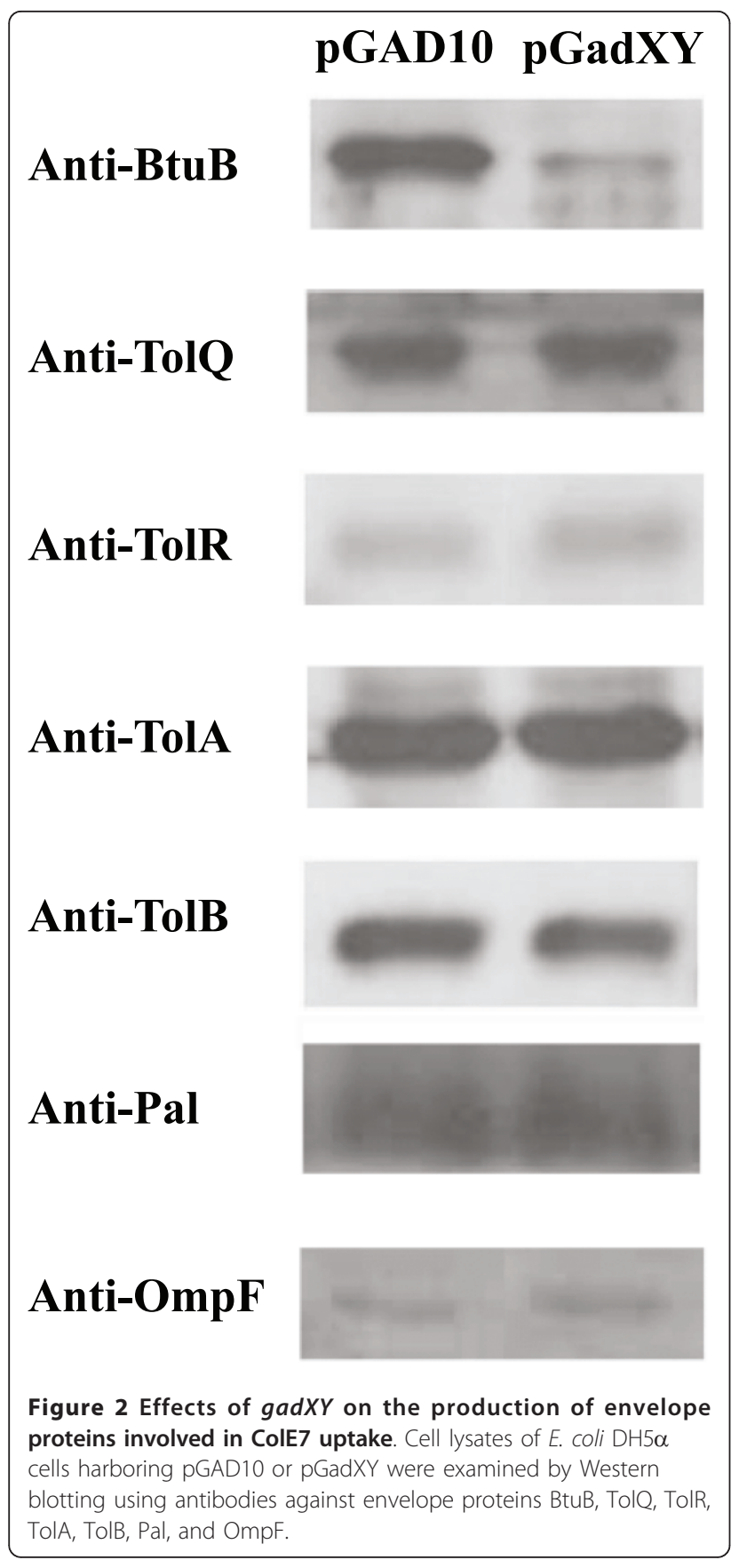

gadX and $20.3 \%$ by gadY, but was decreased $54.4 \%$ by $\operatorname{gad} X Y$ (Table 3).

\section{Binding of GadX to btuB promoter}

GadX has been shown to be a DNA binding protein and can bind to the gadA or the gadB promoter. To determine whether GadX also binds to the btuB promoter, the DNA mobility shift assay was performed. Only GadX was assayed because gad $Y$ does not encode any proteins. The 461-bp DNA fragment containing the

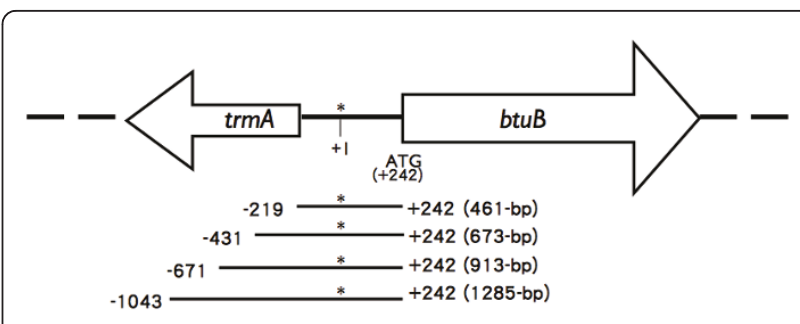

Figure 3 DNA fragments containing the btuB promoter used for lacZ fusions. The btuB initiation codon ATG is located at nucleotide position +242 . Asterisk indicates the first nucleotide of the btuB mRNA. The trmA (tRNA methyltransferase) gene is located upstream from btuB. It has no known effect on btuB expression.

btuB promoter was labeled with ${ }^{32} \mathrm{P}$ and incubated with 2, 4, or 6 pmoles of purified GadX protein (MalE-GadX) that was fused to the maltose binding protein. The DNA fragment containing the promoter of $\operatorname{gadA}$ or $\operatorname{gadB}$ was used as the positive control for GadX binding, and the DNA fragment containing the pal promoter was used as the negative control. As shown in Figure 4, DNA band shift was observed on $\operatorname{gadA}$ and $\operatorname{gadB}$ promoter fragments but not on the negative control. Band shift was also observed on the $b t u B$ promoter fragment in a dose-dependent manner, indicating that GadX binds to the $b t u B$ promoter.

\section{Identification of binding sequence of GadX on btuB promoter}

DNase I footprinting was then performed to determine the binding sequence of $\operatorname{GadX}$ on the $b t u B$ promoter. The 461-bp DNA fragment containing the btuB promoter was labeled with ${ }^{32} \mathrm{P}$ and incubated with 0,2 , 4, or 8 pmoles of purified MalE-GadX protein and then digested with DNase I. Results shown in Figure 5 revealed three MalE-GadX protein binding sites that included nucleotide positions $+56-+81$ (I), $+96-+105$

\section{Table 2 Effect of gadXY on btuB promoter}

\begin{tabular}{|c|c|c|}
\hline Plasmid & $\beta$-galactosidase activity $^{\mathrm{a}}$ & $\%$ inhibition $^{\mathrm{b}}$ \\
\hline (A): pGAD10 + pC-lacZ & 0 & \\
\hline (B): pGadXY + pC-lacZ & 0 & \\
\hline$(A): p G A D 10+p C B_{461} l a c Z$ & $6.4 \pm 0.2$ & 45.7 \\
\hline (B): pGadXY + pCB ${ }_{461} l a c Z$ & $3.5 \pm 0.2$ & \\
\hline (A): pGAD10 + pCB 673 lacZ & $7.2 \pm 0.1$ & 47.1 \\
\hline (B): pGadXY + pCB 673 lacZ & $3.8 \pm 0.1$ & \\
\hline (A): pGAD10 + pCB ${ }_{913} l a c Z$ & $4.8 \pm 0.2$ & 54.5 \\
\hline (B): pGadXY + pCB ${ }_{913}$ lacZ & $2.2 \pm 0.5$ & \\
\hline (A): pGAD10 + pCB 1285 lacZ & $37.5 \pm 0.7$ & 56.7 \\
\hline (B): pGadXY + pCB 1285 lacZ & $16.2 \pm 0.5$ & \\
\hline
\end{tabular}

${ }^{\mathrm{a} M i l l e r}$ unit.

${ }^{\mathrm{b}}$ Caculated according to the following equation: 1 - [ $\beta$-galactosidase activity of (B) $\div \beta$-galactosidase activity of $(A)] \times 100 \%$. 
Table 3 Effect of gadX, gadY, and gadXY on btuB promoter

\begin{tabular}{|c|c|c|}
\hline Plasmids & $\beta$-galactosidase activity ${ }^{a}$ & $\%$ inhibition $^{\mathbf{b}}$ \\
\hline (A): pGAD10/pC-lacZ & 0 & \\
\hline (B): pGAD10/pCB 1285 lacZ & $48.8 \pm 3.9$ & \\
\hline (C): pGadXY/pCB 1285 lacZ & $22.3 \pm 0.7$ & 54.4 \\
\hline (D): pGadX/pCB 1285 lacZ & $38.9 \pm 2.6$ & 20.5 \\
\hline (E): pGadY/pCB 1285 lacZ & $38.9 \pm 2.0$ & 20.3 \\
\hline
\end{tabular}

${ }^{\text {a }}$ Miller unit.

${ }^{\mathrm{b}}$ Calculated according to the following equation: 1 - [ $\beta$-galactosidase activity of (C), (D), or $(E) \div \beta$-galactosidase activity of $(A)] \times 100 \%$.

(II) and $+123-+137$ (III) on the $5^{\prime}$ untranslated region of $b t u B$.

\section{Decreased btuB expression under acidic conditions}

It is known that gadX and gad $Y$ are more highly expressed under acidic environments in stationary phase [15-19,28]. To determine whether the expression of btuB is also repressed in an acidic condition, wild type BW25113 cells were cultured in LB medium $\mathrm{pH} 7.4$ or buffered with $100 \mathrm{mM}$ MES pH5.5. Stationary phase cells grown in different culture media were collected and then assayed for the transcriptional level of $b t u B$ by quantitative real-time PCR. The cDNA amplification comparison results showed the transcription of $\operatorname{gadX}$ with 1.4-fold increase but the level of $b t u B$ was reduced to $57 \%$ (Table 4 ).

\section{Discussion}

Although it has been suggested that the expression of $b t u B$ in $E$. coli is also regulated at the transcriptional level, the trans-acting regulators of $b t u B$ had not been identified $[40,41]$. In this study, we used the ColE7 resistance assay to search for such regulators and found that both $\operatorname{gad} X$ and $\operatorname{gad} Y$ genes can repress the production of BtuB rendering E. coli DH5 $\alpha$ cells resistant to ColE7. Introduction of $\mathrm{pGadX}$, which contains a $\operatorname{gadX}$ gene, into DH5 $\alpha$ cells caused $3.6 \%$ of the cells to become resistant to $2.6 \mathrm{ng} / \mathrm{ml}$ of ColE7. In a similar experiment, pGadY which contains the gadY gene enabled 9.1\% of the cells to grow in the presence of the same concentration $(2.6 \mathrm{ng} / \mathrm{ml}$ ) of ColE7 (Table 1). Although gad $Y$ does not encode any proteins, it had a greater effect on making E. coli resistant to ColE7 than gadX. This is probably due to the binding of $\operatorname{gad} Y$ RNA derived from pGadY to the $\operatorname{gad} X$ mRNA produced by the $\operatorname{gad} X$ gene in the chromosome. This binding stabilizes gadX mRNA so that more GadX protein is produced to suppress the production of BtuB, making the cells resistant to ColE7. The greatest effect (63.9\% survival in $2.6 \mathrm{ng} / \mathrm{ml}$ ColE7) on ColE7 resistance was seen when pGadXY, which contains both $\operatorname{gadX}$ and $\operatorname{gad} Y$ genes, was introduced into the cells. Since pGadXY is a high copy number plasmid, more gadX and gadY mRNAs would be produced and thus more GadX protein would be synthesized to suppress BtuB synthesis. However, excess GadX had adverse effects as over expression of GadX with a strong promoter, such as the T5-lacO promoter, was found to have toxic effect to E. coli [19]. Therefore, expression of $\operatorname{gadX}$ and $\operatorname{gad} Y$ in this study was driven by their own promoters.

Since GadX is a known transcriptional regulator $[14-16,18,19,42]$, the decrease in BtuB expression is due

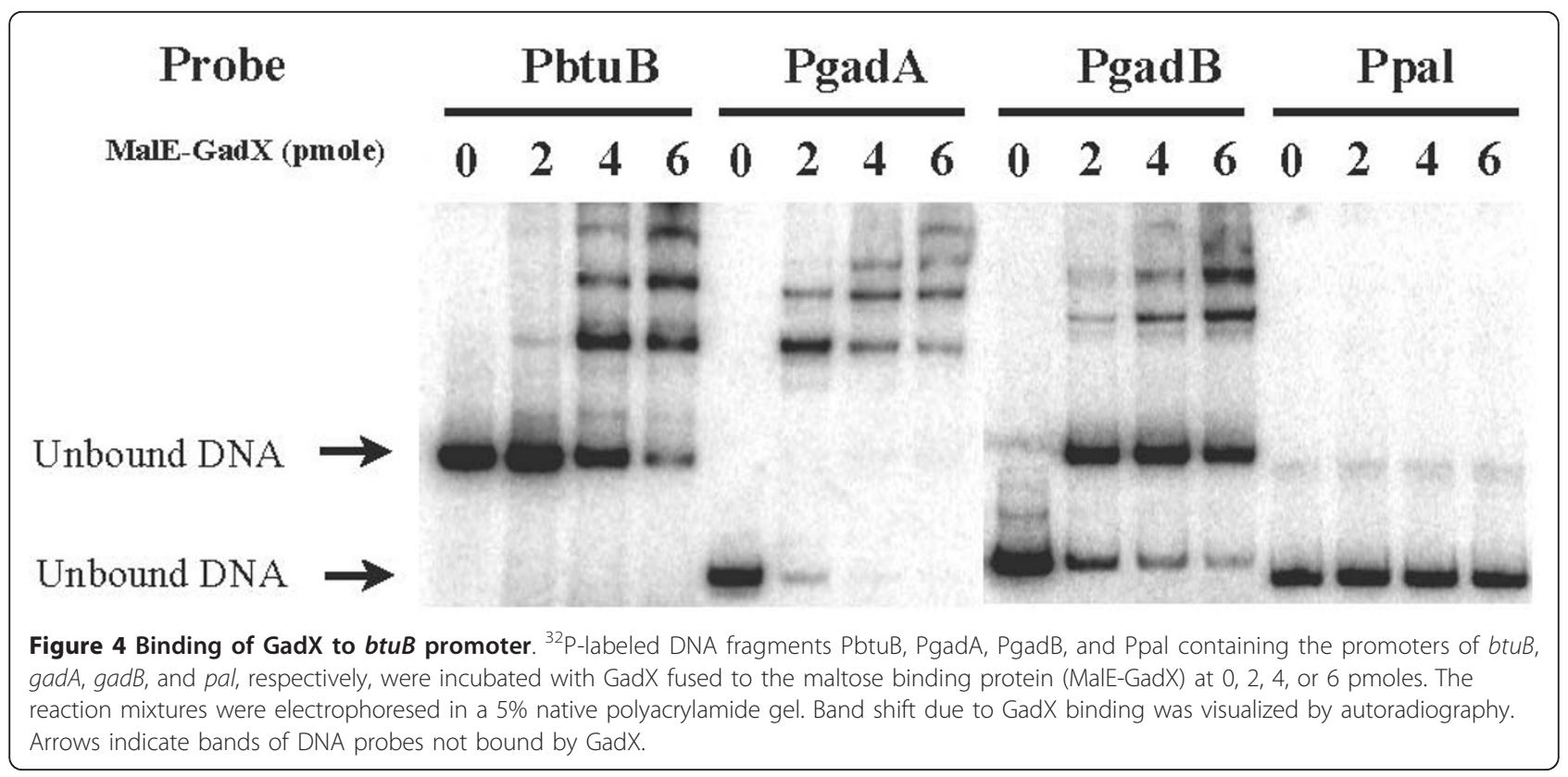




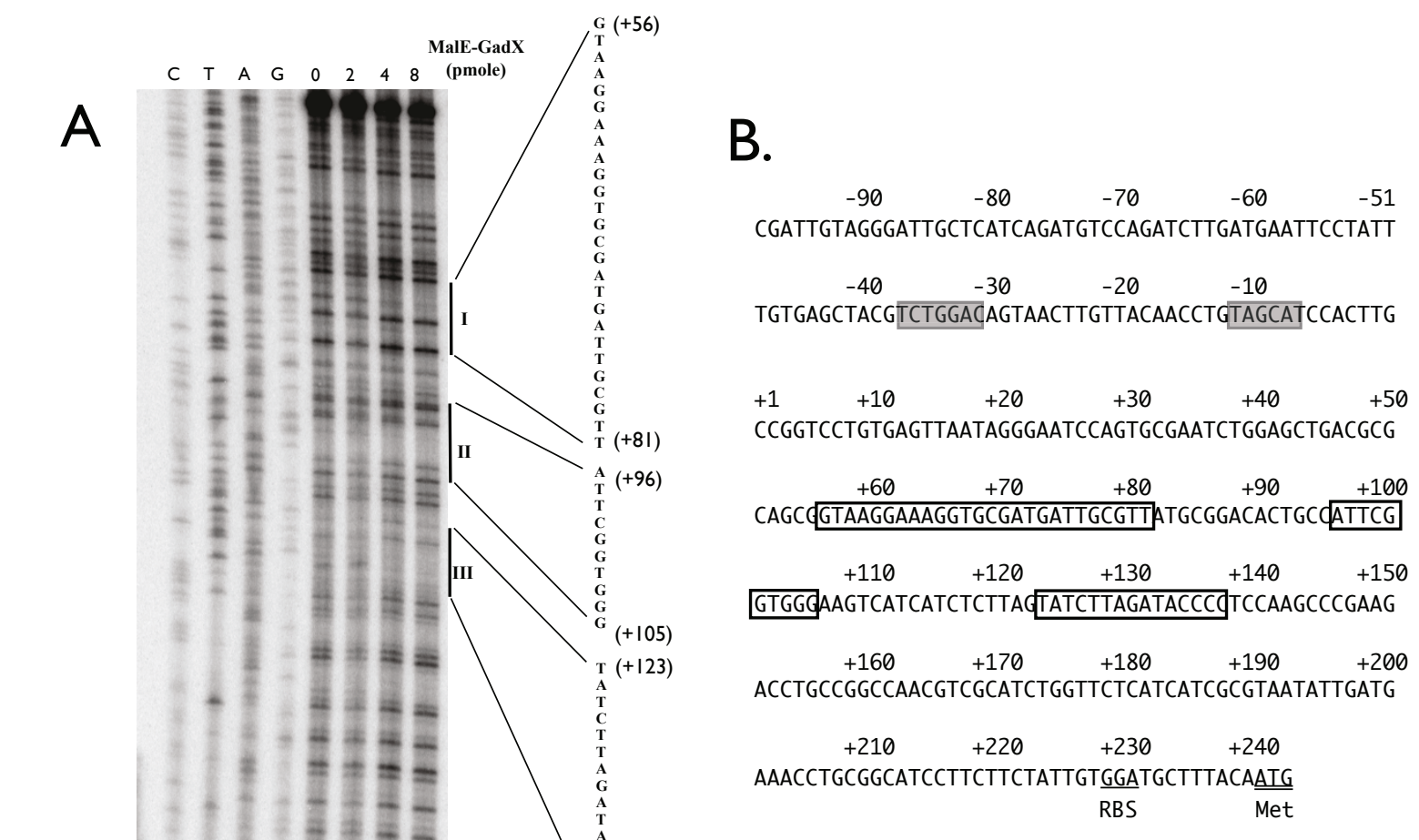

Figure 5 Binding sequence of GadX on btuB promoter. (A) The 461-bp DNA fragment containing btuB promoter was labeled at 5 ' end with ${ }^{32} \mathrm{P}$, incubated with $0,16,24,32$, or 40 pmoles of MalE-GadX, and then subjected to DNase I footprinting. A Sanger's DNA sequencing reaction was also done on the 461-bp fragment to reveal GadX binding sequences. All reactions were electrophoresed in a $6 \%$ urea-acrylamide gel, and the DNA bands were detected by autoradiography. The GadX bound regions are indicated with vertical lines, and the binding sequence of GadX are shown. (B) Sequence of the btuB promoter region. The boxed sequences are GadX binding sequences determined by the DNase I footprinting. The shaded sequences are -10 and -35 regions of the btuB promoter. The initiation codon of btuB is underlined.

to its transcriptional repression by GadX. Our data showed that the $b t u B$ promoter activity was reduced by approximately $50 \%$ in the presence of $\operatorname{gadXY}$ (Table 2 ), most likely due to binding of GadX to the 5 ' untranslated region of $b t u B$ as DNase I footprinting experiment revealed binding of GadX to nucleotides positions +56 +81 (I),$+96-+105$ (II) and +123 - +137 (III) downstream

Table 4 Fold changes of transcripts of $\operatorname{gadX}$ and btuB attribute to different $\mathrm{pH}$ medium (pH 5.5/pH 7.4) from early stationary phase

\begin{tabular}{cc}
\hline Gene & Fold increase $^{\mathrm{a}}$ \\
\hline gadX & $1.43 \pm 0.07$ \\
btuB & $0.57 \pm 0.13$ \\
\hline
\end{tabular}

Experiments were performed in triplicate and the data are presented as mean values $\pm S D$. from the $b t u B$ transcription initiation site (Figure 5). From the sequence alignment of GadX binding sites on $b t u B, \operatorname{gad} A$, and $\operatorname{gadBC}$ regulatory regions[42], we found that sequence in the region I (the 31 nucleotides) has $62.5 \%$ identity (+52-AGCGGTAAGGAAAGGTGCGATGATTGCGTTAT-+82, underlined nucleotides indicate the protected region) with $\operatorname{gadBC}$ and sequence in the region III (the 26 nucleotides) has $60.7 \%$ identity $(+106-$ AAGTCATCATCTCTTAGTATCTTAGATA-+133, underlined nucleotides indicate the protected region) with $\operatorname{gadA}$ regulatory region. From the footprinting result, the GadX binding sites on 5' untranslated region of $b t u B$ share only partial homology with the 42 nucleotides consensus sequence which was reported by Tramonti et. al.[42]. The sequence analysis also revealed the $b t u B$ expression was regulated by the binding of GadX 
on its 5' untranslated region. Binding of transcriptional regulator to the 5' untranslated region to regulate gene expression is also seen in the glp regulon of $E$. coli, in which four repressor binding sites are located at -41 to $-60,-9$ to $-28,+12$ to -8 , and +52 to +33 of the $g l p A C B$ genes [43]. In addition, two IHF binding sites are present downstream from the $g l p T$ transcriptional start site at positions +15 to +51 and +193 to +227 [44].

In the $b t u B$ promoter assay experiment, different lengths of DNA fragments containing $b t u B$ promoter were fused to lacZ. The minimum length of DNA fragment with $b t u B$ promoter activity was 461 bp spanning -219 to +242 nucleotides relative to the translation initiation site of $b t u B$. No significant difference in promoter activity was observed when the 5 ' end of these fragments was extended to -671 . However, a 6 fold $(37.5$ vs. 6.4 $\beta$-galactosidase units, Table 2 ) increase in promoter activity was detected when the DNA fragment was extended to -1043 with a total length of $1,285 \mathrm{bp}$ as compared to that of the 461-bp fragment. It is very likely that a certain transcription regulator binds to the region between -1043 and -671 and enhances the expression of $b t u B$. The $\beta$-galactosidase activity in these assays was not very high because the lac $Z$ fusions were constructed using the single copy plasmid vector $\mathrm{pCC}_{\mathrm{Bac}}^{\mathrm{TM}}$ (Epicentre). The purpose of using the single copy number plasmid in this experiment was to mimic the natural state of $b t u B$ expression in E. coli. In fact, the promoter activity of $b t u B$ is lower than other membrane protein, we have determined the $o m p C$ promoter activity, under the same test condition the Miller's Units of lac $Z$ driven by ompC promoter is 8 folds higher than that of $b t u B$ (data not shown).

Although the results of footprinting and reporter assay revealed that the GadX binding sites on btuB 5' untranslated region share only partial homology with the GadX binding consensus sequence[42] and showing 50\% down regulation in the reporter assay, the expression of $b t u B$ was indeed controlled by GadX.

Both $\operatorname{gadX}$ and $\operatorname{gad} Y$ genes belong to a group of genes that are induced by acid stress under stationary growth phase [44]. Our data showed that the expression of btuB was indeed reduced when $E$. coli cells were grown to stationary phase in an acidic medium as compared to the same cells grown in neutral medium (Table 4). The reduction in the production of $b t u B$ in response to acid stress probably represents a physiological regulatory mechanism of bacteria facing environmental challenges such as low $\mathrm{pH}$. Under stress environment, bacteria need to alter their metabolism to adapt to the environmental change. The transportation of cobalamin by $\mathrm{Btu} B$ receptor is driven by proton motive force (PMF) [45]. Since the PMF of bacteria is increased at low $\mathrm{pH}$ [46], the cobalamin transportation may be enhanced by increased PMF. The higher concentration of cobalamin in cytoplasm will initiate riboswitch mechanism to repress the translation of $B t u B$ receptor, which is in good accord with the repression of $b t u B$ transcription by the acid-induced GadX for bacteria to decrease the production of BtuB in response to this acidic stress.

\section{Conclusions}

Through biological and biochemical analysis, we have demonstrated the GadX can directly interact with $b t u B$ promoter and affect the expression of $b t u B$. When bacteria were grown to stationary phase in an acidic medium, the increased gadX expression would repress the $b t u B$ transcription to help bacteria to adapt to acidic shock. In conclusion, this study provides the first evidence that the expression of $b t u B$ gene is transcriptionally repressed by the acid responsive genes $\operatorname{gad} X$ and $\operatorname{gad} Y$.

\section{Methods}

\section{Plasmid constructions}

To produce the $\mathrm{His}_{6}$-tagged ColE7/Im7 protein complex for the ColE7 resistance assay, pQE30 ${ }_{\mathrm{ColE7}-\mathrm{Im} 7}$ was constructed. The cea7-cei7 genes encoding the colicin E7 and immunity proteins, that form an active ColE7 complex, were amplified from plasmid K317 [47] by PCR using primers F/cea7-BamHI and R/cei-PstI (Table 5). The 1,996-bp PCR product thus generated was inserted between BamHI and PstI sites of pQE30 (Qiagen), fusing the $\mathrm{His}_{6}$-tag to the $\mathrm{N}$ terminus of ColE7. For searching transcriptional regulators of $b t u B$, a genomic library of $E$. coli $\mathrm{K}-12$ strain constructed with the pGAD10 vector (Figure 1) was purchased from Clontech (catalog number XL4001AB) and transformed into E. coli strain DH5 $\alpha$. The plasmid pGadXY (Figure 1) was isolated from the library in this study. To investigate the effect of GadX on $b t u B$ expression, pGadX was constructed as follows. A 1,077-bp DNA fragment containing gadX was generated by PCR using pGadXY (Figure 1) as the template and the MATCHMAKER 5' insert screening sequence 5'-TACCACTACAATGGATG-3' (Clontech) and R/gadX-Pst (Table 5) as primers. This $1.1-\mathrm{kb}$ PCR fragment was inserted into pGEM- $\mathrm{T}_{\text {Easy }}$ (Promega) by TA cloning, generating pGEMgadX. The $1.1-\mathrm{kb}$ fragment was then isolated from pGEMgadX by EcoRI digestion and inserted into the EcoRI site of pGAD10, resulting in pGadX (Figure 1). To investigate the effect of $\operatorname{gad} Y$ on $b t u B$ expression, pGadY (Figure 1) was constructed by deleting the NcoI-DraIII fragment containing gadX from pGadXY.

To assay $b t u B$ promoter activity, DNA fragments (461, 673,913 , and $1,285 \mathrm{bp}$ ) containing different portions (Figure 3 ) of the $b t u B$ promoter was fused to $l a c Z$. These fragments were generated by PCR using primers 
Table 5 Oligonucleotide primers used in this study

\begin{tabular}{|c|c|}
\hline Primer & Sequence 5 '- 3' \\
\hline F/cea7-BamHI & GGATCCATGAGCGGTGGAGATGGACG \\
\hline R/cei7-Pstl & CTGCAGTCAGCCCTGTTTAAATCC \\
\hline F/btuB-219-Xbal & GGCTCTAGAAAACGGTGCCATCATACTTTG \\
\hline R/btuB+242-HindIII & GGCAAGCTTATCATTGTAAAGCATCCACAATAG \\
\hline F/btuB-767 & GTTCACCGTTGCTCGATACC \\
\hline R/btuB-1087 & TCAGATAGATGCCGGTATTACG \\
\hline F/btuB-431-Xbal & GCTCTAGAACGGGATTATTACGC \\
\hline F/btuB-671-Xbal & GCTCTAGATCATCTCTITCCC \\
\hline F/btuB-1043-Xbal & GCTCTAGACCGCTGCGCGGA \\
\hline R/lacZ & TTATTITGACACCAGACC \\
\hline F/gadA-176 & GATCGCCCGAACAGCAA \\
\hline $\mathrm{R} / \operatorname{gad} \mathrm{A}+77$ & CGTGAATCGAGTAGTTC \\
\hline F/gadB-173 & AATAACAGCATAAAACA \\
\hline $\mathrm{R} / \mathrm{gadB}+77$ & CGTGAATCGAGTAGTTCC \\
\hline F/pal-Xbal & $\underline{\text { TCTAGAGAGGCGTACAAGTTCTG }}$ \\
\hline R/pal-HindIII & AAGCTTATCATTTCAATGATTCCTTTAC \\
\hline F/gadX-BamHI & GGATCCATGCAACCACTACATGG \\
\hline$R / g a d X-P s t 1$ & CTGCAGCTATAATCTTATTCCTT \\
\hline F/gadX-393 & TATACCGCTGCTTCTGAACG \\
\hline$R / g a d X-726$ & TCGCTCCTGATACTCTGTGG \\
\hline F/rrsA-483 & CGTTACCCGCAGAAGAAGC \\
\hline $\mathrm{R} / \mathrm{rrs} \mathrm{A}-808$ & GTGGACTACCAGGGTATCTAATCC \\
\hline
\end{tabular}

The underlined letters indicate restriction sites.

F/btuB-219-XbaI, F/btuB-431-XbaI, F/btuB-671-XbaI, and F/btuB-1043-XbaI paired with the 3' primer R/btuB $+242-$ HindIII (Table 5). The resulting PCR products

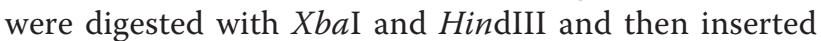
into corresponding sites on pKM005 that carries a promoterless lac $Z$ gene [48], generating $\mathrm{pKMbtuB}_{461}$-lacZ, $\mathrm{pKMbtuB}_{673}$-lacZ, pKMbtuB ${ }_{913}$-lacZ, and pKMbtuB ${ }_{1285^{-}}$ lacZ. To mimic native expression of btuB, these btuB$l a c Z$ fusions were transferred to the single copy plasmid vector $\mathrm{pCC} 1$ (Epicentre). The fragments containing $b t u B$ promoter and lac $Z$ on pKM005 derivatives were amplified with primers F/btuB-219-XbaI, F/btuB-431-XbaI, F/ btuB-671-XbaI, and F/btuB-1043-XbaI paired with the 3' primer R/lacZ (Table 5), and the resulting 3.3, 3.5, 3.74 , and $4.1-\mathrm{kb}$ DNA fragments were separately inserted into pGEM- $\mathrm{T}_{\text {Easy }}$ (Promega) by TA cloning. The 3.3, 3.5, 3.74, and 4.1-kb fragments were then isolated from these pGEM- $\mathrm{T}_{\text {Easy }}$ derivatives by Not I digestion and inserted into the NotI site of pCC1 vector, generating $\mathrm{pCB}_{461}$ lacZ, $\mathrm{pCB}_{673}$ lacZ, $\mathrm{pCB}_{913}$ lacZ, and $\mathrm{pCB}_{1285}$ lac $Z$. The plasmid $\mathrm{pC}$-lac $Z$ that contains a promoterless lac $Z$ gene inserted into $\mathrm{pCC} 1$ vector was used as a negative control. To produce GadX for DNA binding assay, pMalE-GadX that contains maltose-binding protein fused to GadX (MalE-GadX) was constructed. The 825-bp DNA fragment containing $g a d X$ was generated by PCR using pGadXY as the template and F/
gadX-BamHI and R/gadX-PstI (Table 5) as primers and then ligated between the BamHI and Pst sites of pMAL-C2X (New England Biolab), resulting in pMalEGadX.

\section{Production of ColE7}

To produce the $\mathrm{His}_{6}$-tagged ColE7/ImE7 complex, E. coli strain XL1-Blue containing plasmid $\mathrm{pQE30}$ ColE7-Im7 $_{\text {Im }}$ was cultured in LB medium containing ampicillin (50 $\mu \mathrm{g} / \mathrm{ml})$ and tetracycline $(20 \mu \mathrm{g} / \mathrm{ml})$. When the bacterial growth reached $\mathrm{OD}_{600} \sim 1.0$, IPTG was added to a final concentration of $1 \mathrm{mM}$. After a 2-hr induction, bacteria were harvested by centrifugation at $6,500 \times \mathrm{g}$ for $20 \mathrm{~min}$ and then resuspended in HB buffer $(20 \mathrm{mM}$ Tris, 150 $\mathrm{mM} \mathrm{NaCl}, 30 \mathrm{mM}$ imidazole, pH8.0). The resuspended bacteria were lysed with a French Pressure Cell (SLM Instruments, Inc. Urbane, IL), and the cell lysate was centrifuged at $48,000 \times \mathrm{g}$ for 1 hour. The clarified supernatant was passed through a ProBond ${ }^{\mathrm{TM}}$ nickelnitrilotriacetic acid resin affinity column (Invitrogen, Carlsbad, CA) to purify the $\mathrm{His}_{6}$-tagged ColE7/ImE7 according to manufacture's protocol (Invitrogen, Carlsbad, CA).

\section{Antibody preparation for detection of protein whose expression is affected by gadXY}

To prepare antibodies against envelope proteins BtuB, TolQ, TolR, TolA, TolB, Pal, and OmpF, the coding region of each protein was fused inframe with $\mathrm{His}_{6}$-tag in the plasmid pQE30 (Qiagen), respectively. The His $6^{-}$ tagged proteins were then expressed and purified using the same method as described for $\mathrm{His}_{6}$-tagged ColE7/ ImE7 and sent to the company to prepare polyclonal antibodies. The specificities of these antibodies were confirmed by Western blotting using these antibodies as reported by Pan et. al[49].

\section{DNA binding assay}

The electrophoretic mobility shift assay was performed to investigate binding of $\mathrm{GadX}$ to the $b t u B$ promoter. To obtain purified MalE-GadX protein, E. coli strain XL-1 Blue containing pMalE-GadX was grown in $100 \mathrm{ml}$ of LB containing ampicillin $(50 \mu \mathrm{g} / \mathrm{ml})$ and $0.2 \%$ glucose to $\mathrm{OD}_{600} \sim 1.0$. IPTG was then added to a final concentration of $1 \mathrm{mM}$. After $2 \mathrm{hr}$ of incubation, the cells were pelleted, resuspended in maltose binding buffer (20 mM Tris- $\mathrm{HCl} \mathrm{pH} \mathrm{8.0,} 200 \mathrm{mM} \mathrm{NaCl})$, and lysed with a French Pressure Cell. The cell lysate was centrifuged at $48,000 \times \mathrm{g}$ for $1 \mathrm{hr}$, and the supernatant was subjected to an amylose resin affinity chromatography (New England BioLabs) to purify the MalE-GadX protein.

To make probes for the DNA binding assay, a 461-bp (Figure 3,-219-+242) DNA fragment containing the 
btuB promoter was amplified with primers F/btuB-219$X b a I$ and R/btuB+242-HindIII (Table 5) by PCR. The DNA fragment containing the promoter of $\operatorname{gadA}(-176$ $+77,253 \mathrm{bp})$ or $\operatorname{gadB}(-173-+77,250 \mathrm{bp})$ was used as the positive control, which were amplified with primer pairs $\mathrm{F} / \operatorname{gadA}-176$ and $\mathrm{R} / \operatorname{gad} \mathrm{A}+77$ and $\mathrm{F} / \operatorname{gadB}-173$ and $\mathrm{R} / \operatorname{gad} \mathrm{B}+77$ (Table 5), respectively, as described by Tramonti et al. [19]. The DNA fragment containing the upstream noncoding region of pal was used as the negative control, which was amplified with primers F/pal$X b a \mathrm{I}$ and R/pal-HindIII (Table 5). These DNA fragments were end-labeled with $\left[\gamma-{ }^{32} \mathrm{P}\right]$ ATP by T4 polynucleotide kinase (New England BioLabs). The labeled DNA fragments $(6 \mathrm{fmol})$ were incubated with the MalE-GadX protein at room temperature for $20 \mathrm{~min}$ in $10 \mu \mathrm{l}$ of binding buffer [19]. Samples were then loaded on a $5 \%$ nondenaturing polyacrylamide gel in $0.5 \mathrm{X}$ TBE buffer and electrophoresed for $35 \mathrm{~min}$ at room temperature. The gels were then dried and autoradiographed.

\section{DNase I footprinting}

DNase I footprinting was performed to determine the binding sequence of MalE-GadX on btuB promoter as described by Tramonti et al [19]. Thirty $\mu$ l of reaction mixture that contains $5 \mathrm{ng}$ of ${ }^{32} \mathrm{P}$-labeled 461-bp btuB promoter fragment, various amounts of the MalE-GadX protein, and reaction buffer (40 mM HEPES pH 8.0, $100 \mathrm{mM}$ potassium chloride, and $10 \mathrm{mM}$ magnesium acetate) was incubated at room temperature for $20 \mathrm{~min}$. At the end of the incubation, 0.5 U DNase I (Roche Biochemicals, Indianapolis, IN) was added to each reaction mixture and then incubated at $37^{\circ} \mathrm{C}$ for $1 \mathrm{~min}$ followed by addition of $3 \mu \mathrm{l}$ of quench solution $(0.1 \%$ xylene cyanol, $4 \%$ SDS, and $50 \%$ glycerol) to stop the DNase I digestion. The partially digested product was passed through a Sephadex G25 spin column (GE Healthcare), and the eluate was subjected to 30 cycles of asymmetric PCR (SequiTherm Excel ${ }^{\mathrm{TM}} \mathrm{II}$, Epicentre) using 5'-end ${ }^{32} \mathrm{P}$-labeled primer $\mathrm{R} / \mathrm{btuB}+242$-HindIII (Table 5). The PCR-generated products were electrophoresed on a $6 \%$ sequencing gel. The gel was then dried and autoradiographed. To determine the binding sequence of GadX, the 461-bp btuB DNA probe was sequenced by the Sanger's sequencing method using the 5 '-end ${ }^{32} \mathrm{P}$-labeled primer R/btuB+242-HindIII (Table 5).

\section{Quantitative Real-Time Polymerase Chain Reaction}

Total RNA of wild type Escherichia coli strain BW25113 grown under LB ( $\mathrm{pH} 7.4$ ) or LB/MES (LB buffered with $100 \mathrm{mM}$ MES, pH 5.5) to early stationary phase were isolated using a modified hot-phenol extraction method [21]. This was followed by further purification using RNAspin Mini RNA purification kit (GE) to remove contaminating genomic DNA and enhance the quality of RNA. Each cDNA sample was synthesized from 0.1 $\mu g$ total RNA with specific primers of $\operatorname{rrs} A, \operatorname{gad} X$ and $b t u B$ using RevertAid ${ }^{\mathrm{TM}}$ First strand cDNA synthesis kit (Fermentas). Following reverse transcription, specific gene transcription levels were determined by quantitative real-time PCR using the ABI PRISM 7700 Sequence Detection System (Applied Biosystem). Real-time PCR was performed with each specific primer pair using SYBR Green PCR Master mix (MBI). For $\operatorname{rrs} A$, primer pair rrsA $\mathrm{F}$ and rrsA $\mathrm{R}$ was used; for $\operatorname{gadX}$, primer pair $\operatorname{gad} X \mathrm{~F}$ and $\operatorname{gadX} \mathrm{R}$ was used; and for $b t u B$, primer pair btub $\mathrm{F}$ and btub $\mathrm{R}$ was used (Table 5). The rrsA of $16 \mathrm{~S}$ rRNA was chosen as the normalizing gene. The expression levels of $\operatorname{gad} X$ and $b t u B$ of cells grown in medium with different $\mathrm{pH}$ and different growth were compared.

\section{Acknowledgements}

We thank Dr. Chao-Hung Lee for discussion and critical editing of this manuscript. This work was supported by grants from Ministry of Education, Aim for the Top University Plan (96A-D-T130, 97A-C-T130, 98A-C-T131, and 99A-C-T130) to S.-T. H, and the National Science Council, Taiwan R. O. C. (NSC92-2321-B-010-007, NSC93-2321-B-010-008, and NSC94-2321-B-010-002) to S.-T. H.

\section{Author details}

${ }^{1}$ Institute of Microbiology and Immunology, School of Life Science, National Yang-Ming University, Taipei 11221, Taiwan. ${ }^{2}$ Institute of Biological Chemistry, Academia Sinica, Taipei 11529, Taiwan. ${ }^{3}$ Institute of Biochemistry, National Yang Ming University, Taipei, 11221, Taiwan. ${ }^{4}$ Department of Biotechnology and Laboratory Science in Medicine, National Yang-Ming University, Taipei 11221, Taiwan. ${ }^{5}$ Department of Education and Research, Taipei City Hospital, Taipei, Taiwan.

\section{Authors' contributions}

GSL designed and performed most of the experiments, analyzed data and wrote the manuscript. STH designed, supervised all the experiments, analyzed data and wrote the manuscript. KFC provided ColE7 for colicin assay and gave suggestions. PHL provided the antibodies against BtuB, TolQ, TolR, TolA, TolB, Pal, and OmpF for this research. WJS and WSH gave suggestions and analyzed data for this research.

All the authors have read and approved the final manuscript.

\section{Competing interests}

The authors declare that they have no competing interests.

Received: 18 June 2010 Accepted: 11 February 2011

Published: 11 February 2011

\section{References}

1. Heller K, Mann BJ, Kadner RJ: Cloning and expression of the gene for the vitamin B12 receptor protein in the outer membrane of Escherichia coli. J Bacteriol 1985, 161(3):896-903.

2. Roth JR, Lawrence JG, Bobik TA: Cobalamin (coenzyme B12): synthesis and biological significance. Annu Rev Microbiol 1996, 50:137-181.

3. Bradbeer C, Woodrow ML, Khalifah LI: Transport of vitamin B12 in Escherichia coli: common receptor system for vitamin B12 and bacteriophage BF23 on the outer membrane of the cell envelope. J Bacteriol 1976, 125(3):1032-1039.

4. Lundrigan MD, Kadner RJ: Altered cobalamin metabolism in Escherichia coli btuR mutants affects btuB gene regulation. J Bacteriol 1989, 171(1):154-161.

5. Escalante-Semerena JC, Suh SJ, Roth JR: cobA function is required for both de novo cobalamin biosynthesis and assimilation of exogenous corrinoids in Salmonella typhimurium. J Bacteriol 1990, 172(1):273-280. 
6. Crouzet J, Levy-Schil S, Cameron B, Cauchois L, Rigault S, Rouyez MC, Blanche F, Debussche L, Thibaut D: Nucleotide sequence and genetic analysis of a 13.1-kilobase-pair Pseudomonas denitrificans DNA fragment containing five cob genes and identification of structural genes encoding $\mathrm{Cob}(\mathrm{I})$ alamin adenosyltransferase, cobyric acid synthase, and bifunctional cobinamide kinasecobinamide phosphate guanylyltransferase. J Bacteriol 1991, 173(19):6074-6087.

7. Nou X, Kadner RJ: Coupled changes in translation and transcription during cobalamin-dependent regulation of btuB expression in Escherichia coli. J Bacteriol 1998, 180(24):6719-6728.

8. Nou X, Kadner RJ: Adenosylcobalamin inhibits ribosome binding to btuB RNA. Proc Natl Acad Sci USA 2000, 97(13):7190-7195.

9. Nahvi A, Sudarsan N, Ebert MS, Zou X, Brown KL, Breaker RR: Genetic control by a metabolite binding mRNA. Chem Biol 2002, 9(9):1043-1049.

10. Richter-Dahlfors AA, Andersson DI: Cobalamin (vitamin B12) repression of the Cob operon in Salmonella typhimurium requires sequences within the leader and the first translated open reading frame. Mol Microbiol 1992, 6(6):743-749.

11. Ravnum S, Andersson DI: Vitamin B12 repression of the btuB gene in Salmonella typhimurium is mediated via a translational control which requires leader and coding sequences. Mol Microbiol 1997, 23(1):35-42.

12. Rodionov DA, Vitreschak AG, Mironov AA, Gelfand MS: Comparative genomics of the vitamin B12 metabolism and regulation in prokaryotes. J Biol Chem 2003, 278(42):41148-41159.

13. Nahvi A, Barrick JE, Breaker RR: Coenzyme B12 riboswitches are widespread genetic control elements in prokaryotes. Nucleic Acids Res 2004, 32(1):143-150

14. Shin S, Castanie-Cornet MP, Foster JW, Crawford JA, Brinkley C, Kaper JB: An activator of glutamate decarboxylase genes regulates the expression of enteropathogenic Escherichia coli virulence genes through control of the plasmid-encoded regulator, Per. Mol Microbiol 2001, 41(5):1133-1150.

15. Ma Z, Richard H, Tucker DL, Conway T, Foster JW: Collaborative regulation of Escherichia coli glutamate-dependent acid resistance by two AraClike regulators, GadX and GadW (YhiW). J Bacteriol 2002, 184(24):7001-7012

16. Castanie-Cornet MP, Penfound TA, Smith D, Elliott JF, Foster JW: Control of acid resistance in Escherichia coli. J Bacteriol 1999, 181(11):3525-3535.

17. Hommais F, Krin E, Laurent-Winter C, Soutourina O, Malpertuy A, Le Caer JP, Danchin A, Bertin P: Large-scale monitoring of pleiotropic regulation of gene expression by the prokaryotic nucleoid-associated protein, H-NS. Mol Microbiol 2001, 40(1):20-36

18. Ma Z, Richard H, Foster JW: pH-Dependent modulation of cyclic AMP levels and GadW-dependent repression of RpoS affect synthesis of the GadX regulator and Escherichia coli acid resistance. J Bacterio/ 2003, 185(23):6852-6859.

19. Tramonti A, Visca P, De Canio M, Falconi M, De Biase D: Functional characterization and regulation of gadX, a gene encoding an AraC/XylS-like transcriptional activator of the Escherichia coli glutamic acid decarboxylase system. J Bacteriol 2002, 184(10):2603-2613

20. Waterman SR, Small PL: Transcriptional expression of Escherichia coli glutamate-dependent acid resistance genes gadA and gadBC in an hns rpoS mutant. J Bacteriol 2003, 185(15):4644-4647.

21. De Biase D, Tramonti A, Bossa F, Visca P: The response to stationary-phase stress conditions in Escherichia coli: role and regulation of the glutamic acid decarboxylase system. Mol Microbiol 1999, 32(6):1198-1211.

22. Homola AD, Dekker EE: Decarboxylation of gamma-hydroxyglutamate by glutamate decarboxylase of Escherichia coli (ATCC 11246). Biochemistry 1967, 6(8):2626-2634

23. Giangrossi M, Zattoni S, Tramonti A, De Biase D, Falconi M: Antagonistic role of H-NS and GadX in the regulation of the glutamate decarboxylase-dependent acid resistance system in Escherichia coli. J Biol Chem 2005, 280(22):21498-21505.

24. Yamashino T, Ueguchi C, Mizuno T: Quantitative control of the stationary phase-specific sigma factor, sigma S, in Escherichia coli: involvement of the nucleoid protein H-NS. Embo J 1995, 14(3):594-602.
25. Barth M, Marschall C, Muffler A, Fischer D, Hengge-Aronis R: Role for the histone-like protein $\mathrm{H}-\mathrm{NS}$ in growth phase-dependent and osmotic regulation of sigma $\mathrm{S}$ and many sigma S-dependent genes in Escherichia coli. J Bacteriol 1995, 177(12):3455-3464.

26. Hengge-Aronis R: Back to log phase: sigma $S$ as a global regulator in the osmotic control of gene expression in Escherichia coli. Mol Microbiol 1996, 21(5):887-893.

27. Ma Z, Gong S, Richard H, Tucker DL, Conway T, Foster JW: GadE (YhiE) activates glutamate decarboxylase-dependent acid resistance in Escherichia coli K-12. Mol Microbiol 2003, 49(5):1309-1320.

28. Opdyke JA, Kang JG, Storz G: GadY, a small-RNA regulator of acid response genes in Escherichia coli. J Bacteriol 2004, 186(20):6698-6705.

29. Tucker DL, Tucker N, Ma Z, Foster JW, Miranda RL, Cohen PS, Conway T: Genes of the GadX-GadW regulon in Escherichia coli. J Bacteriol 2003, 185(10):3190-3201

30. Di Masi DR, White JC, Schnaitman CA, Bradbeer C. Transport of vitamin B12 in Escherichia coli: common receptor sites for vitamin B12 and the E colicins on the outer membrane of the cell envelope. J Bacteriol 1973, 115(2):506-513.

31. Riley MA: Positive selection for colicin diversity in bacteria. Mol Biol Evol 1993, 10(5):1048-1059.

32. James R, Kleanthous C, Moore GR: The biology of E colicins: paradigms and paradoxes. Microbiology 1996, 142(Pt 7):1569-1580.

33. Kadner RJ: Repression of synthesis of the vitamin B12 receptor in Escherichia coli. J Bacteriol 1978, 136(3):1050-1057.

34. Kurisu G, Zakharov SD, Zhalnina MV, Bano S, Eroukova WY, Rokitskaya TI, Antonenko YN, Wiener MC, Cramer WA: The structure of BtuB with bound colicin E3 R-domain implies a translocon. Nat Struct Biol 2003, 10(11):948-954.

35. Lazdunski C, Bouveret E, Rigal A, Journet L, Lloubes R, Benedetti H: Colicin import into Escherichia coli cells requires the proximity of the inner and outer membranes and other factors. Int J Med Microbiol 2000, 290(45):337-344

36. Lazdunski CJ, Bouveret E, Rigal A, Journet L, Lloubes R, Benedetti $H$ : Colicin import into Escherichia coli cells. J Bacteriol 1998, 180(19):4993-5002.

37. Isnard M, Rigal A, Lazzaroni JC, Lazdunski C, Lloubes R: Maturation and localization of the TolB protein required for colicin import. J Bacteriol 1994, 176(20):6392-6396

38. Jeanteur D, Schirmer T, Fourel D, Simonet V, Rummel G, Widmer C Rosenbusch JP, Pattus F, Pages JM: Structural and functional alterations of a colicin-resistant mutant of OmpF porin from Escherichia coli. Proc Natl Acad Sci USA 1994, 91(22):10675-10679.

39. Miller JH: Experiments in molecular genetics. Cold Spring Harbor Laboratory, Cold Spring Harbor, NY; 1972.

40. Franklund CV, Kadner RJ: Multiple transcribed elements control expression of the Escherichia coli btuB gene. J Bacteriol 1997, 179(12):4039-4042

41. Lundrigan MD, Koster W, Kadner RJ: Transcribed sequences of the Escherichia coli btuB gene control its expression and regulation by vitamin B12. Proc Natl Acad Sci USA 1991, 88(4):1479-1483.

42. Tramonti A, De Canio M, De Biase D: GadX/GadW-dependent regulation of the Escherichia coli acid fitness island: transcriptional control at the gadY-gadW divergent promoters and identification of four novel $42 \mathrm{bp} \mathrm{GadX/GadW-specific} \mathrm{binding} \mathrm{sites.} \mathrm{Mol}$ Microbiol 2008, 70(4):965-982.

43. Larson TJ, Cantwell JS, van Loo-Bhattacharya AT: Interaction at a distance between multiple operators controls the adjacent, divergently transcribed glpTQ-glpACB operons of Escherichia coli K-12. J Biol Chem 1992, 267(9):6114-6121.

44. Yang B, Gerhardt SG, Larson TJ: Action at a distance for glp repressor control of glpTQ transcription in Escherichia coli K-12. Mol Microbiol 1997, 24(3):511-521.

45. Bradbeer $C$ : The proton motive force drives the outer membrane transport of cobalamin in Escherichia coli. J Bacteriol 1993, 175(10):3146-3150

46. Kashket ER: Proton motive force in growing Streptococcus lactis and Staphylococcus aureus cells under aerobic and anaerobic conditions. J Bacteriol 1981, 146(1):369-376. 
47. Lu FM, Chak KF: Two overlapping SOS-boxes in ColE operons are responsible for the viability of cells harboring the Col plasmid. Mol Gen Genet 1996, 251(4):407-411.

48. Masui $Y$, Coleman J, Inouye M: Multipurose expression cloning vehicles in E. coli In experimental manipulation of gene expression.Edited by: Inouye M. Academic press, Inc., NY; 1983.

49. Pan YH, Liao CC, Kuo CC, Duan KJ, Liang PH, Yuan HS, Hu ST, Chak KF: The critical roles of polyamines in regulating ColE7 production and restricting ColE7 uptake of the colicin-producing Escherichia coli. J Biol Chem 2006, 281(19):13083-13091.

doi:10.1186/1471-2180-11-33

Cite this article as: Lei et al:: Repression of btuB gene transcription in Escherichia coli by the GadX protein. BMC Microbiology 2011 11:33.

Submit your next manuscript to BioMed Central and take full advantage of:

- Convenient online submission

- Thorough peer review

- No space constraints or color figure charges

- Immediate publication on acceptance

- Inclusion in PubMed, CAS, Scopus and Google Scholar

- Research which is freely available for redistribution

Submit your manuscript at www.biomedcentral.com/submit
() Biomed Central 